\title{
SLURRY NEBULIZATION ICP-OES FOR THE DETERMINATION OF Cu, Fe, Mg, Mn AND Zn IN BOVINE LIVER
}

\author{
Ntebogeng S. Mokgalaka ${ }^{1 *}$, Taddese Wondimu ${ }^{2}$ and Robert I. McCrindle ${ }^{1}$ \\ ${ }^{1}$ Tshwane University of Technology, Department of Chemistry, Arcadia Campus, P.O. Box \\ 56208, Arcadia 0007, South Africa \\ ${ }^{2}$ National University of Lesotho, Department of Chemistry and Chemical Technology, P.O. \\ Roma 180, Lesotho
}

(Received November 17, 2007; revised January 22, 2008)

\begin{abstract}
A method that involves analysis of bovine liver by slurry nebulization and ICP-OES has been developed. This method permits rapid and accurate determination of $\mathrm{Cu}, \mathrm{Fe}, \mathrm{Mg}, \mathrm{Mn}$ and $\mathrm{Zn}$ in bovine liver. Aliquots of freeze-dried and powdered bovine liver sample were dispersed in $2.0 \mathrm{M} \mathrm{HNO}_{3}$ and sonicated to homogenize the resulting slurries. Bovine liver samples were also microwave digested or subjected to aqueous extraction for comparison of analytical results. Concentrations of $\mathrm{Cu}, \mathrm{Fe}, \mathrm{Mg}, \mathrm{Mn}$ and $\mathrm{Zn}$ in aqueous slurries, the digests, and aqueous extracts were determined by the ICP-OES using external calibration curves. A student's $t$ test showed that the results obtained using the slurry method were in good agreement at $95 \%$ confidence level (CL) with those of microwave digestion or aqueous extraction techniques, except for Fe. To check the accuracy and precision of the slurry method, a bovine liver CRM was analyzed and good agreement was achieved with the certified values at $95 \% \mathrm{CL}$. The results demonstrate inefficiency of aqueous extraction technique for complete removal of $\mathrm{Fe}$ in bovine liver sample.
\end{abstract}

KEY WORDS: Bovine liver, ICP-OES, Slurry nebulization, $\mathrm{Cu}, \mathrm{Fe}, \mathrm{Mg}, \mathrm{Mn}, \mathrm{Zn}$

\section{INTRODUCTION}

Trace metals in organs and tissues play a key role in human and animal physiology. At the same time, these metals tend to target organs such as the liver, kidneys, brain and arteries for bioaccumulation [1-7]. An overload or deficiency of trace metals in animals and humans may contribute to several diseases. For example, hyper-accumulation of $\mathrm{Cu}$ and $\mathrm{Fe}$ promotes liver cirrhosis. High levels of $\mathrm{Mg}$ can develop kidney failure whereas those of $\mathrm{Mn}$ and $\mathrm{Zn}$ can result in cancer. Concentrations of trace metals determined in such organs of animals as liver may indicate the degree of contamination of grazing area and drinking water [1,7]. Therefore, the accurate determination of concentrations of trace metals in tissues and organs of animals may help to elucidate the role and function of the trace metals in the living animal and serve as biological indicators of the status of pollution by these metals in the environment $[1,7]$.

The determination of metals in biological tissues generally requires the complete digestion of the organic matrix, although partial digestion methods have been reported in the literature [8]. Sample preparation is one of the most time-consuming steps and also one of the main sources of contamination. Conventional wet-ashing methods using a hotplate require high boiling point acid mixtures and long reaction times. After digestion, filtration or centrifugation [8] is commonly needed, which increases the risk of sample loss or contamination.

The use of microwave (MW) energy as a means to complete acid-assisted wet digestion of biological tissues is now the norm [2, 5, 6, 9-14]. Although open-vessel MW digestion is popular because of its simplicity and capability to handle larger sample sizes, it suffers from the same drawbacks as conventional methods such as corrosion of equipment, loss of analyte and contamination of the sample [15]. The limitations of the open-vessel MW digestion can be overcome by using the closed-vessel MW digestion technique. Although closed-vessel MW

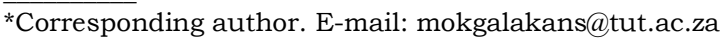


digestion helps in eliminating the organic matrix that may cause physical and chemical interferences during analysis, the limitation in sample size to be digested often poses detection problems with elements occurring at very low concentrations.

The slurry technique may well be an alternative to conventional sample preparation methods for biological tissues [4, 16-20]. This technique has the advantage of simplifying the sample preparation procedure, since it requires minimum modification of the existing instrumentation and no harsh conditions for complete destruction of the matrix. Furthermore, the slurry technique offers reduced manipulation of the sample, lower contamination problems, thus better reproducibility of results, and a reduction in the preparation time. The combination of slurry sampling with atomization techniques such as graphite furnace atomic absorption spectrometry (GFAAS) $[4,16,20]$ has been successfully applied for the determination of trace metals in biological samples. These techniques, however, typically require the addition of chemical modifiers. The introduction of modifier solutions into the plasma is not recommended with the view to avoiding build up of deposits on the torch and also because of plasma loading.

The aim of this work was to explore the feasibility of the slurry nebulization technique as an alternative to conventional methods for the determination of $\mathrm{Cu}, \mathrm{Fe}, \mathrm{Mg}, \mathrm{Mn}$ and $\mathrm{Zn}$ in bovine liver by ICP-OES.

\section{EXPERIMENTAL}

\section{Instrumentation}

All measurements were carried out using a simultaneous Spectro Ciros ${ }^{\mathrm{CCD}}$ ICP-OES (Spectro Instruments, Kleve, Germany). A fixed Fassel-type quartz torch with a $1.6 \mathrm{~mm}$ i.d. injector tube, a Burgener T2002 HP (Burgener Research Inc., Missisauga, Canada) slurry nebulizer and a cyclonic spray chamber (Glass expansion, West Melbourne Vic, Australia) were used. The operating conditions are summarized in Table 1.

Table 1. Instrumental operating conditions of the Spectro Ciros ${ }^{\text {cd }}$ ICP-OES.

\begin{tabular}{|l|l|}
\hline Operating parameter & Setting \\
\hline Forward power & $1500 \mathrm{~W}$ \\
Coolant gas flow rate & $15 \mathrm{~L} \mathrm{~min}^{-1}$ \\
Auxiliary gas flow rate & $0.5 \mathrm{~L} \mathrm{~min}^{-1}$ \\
Nebulizer gas flow rate & $0.8 \mathrm{~L} \mathrm{~min}^{-1}$ \\
Pump speed & $2.0 \mathrm{~mL} \mathrm{~min}$ \\
Horizontal viewing position (x) & $0.0 \mathrm{~mm}$ \\
Vertical viewing position (y) & $+4.0 \mathrm{~mm}$ \\
Wavelength & $\mathrm{Cu}$ (I) $324.754 \mathrm{~nm}$ \\
& Fe (II) $238.204 \mathrm{~nm}$ \\
& $\mathrm{Mg}$ (II) $279.079 \mathrm{~nm}$ \\
& Mn (II) $257.610 \mathrm{~nm}$ \\
& $\mathrm{Zn}$ (I) $213.856 \mathrm{~nm}$ \\
\hline
\end{tabular}

A multipurpose food processor (Orion RS 9005) was used to cut the freeze-dried bovine liver chunks. The resulting powder was ground in a micronizing mill using agate grinding elements (McCrone Instruments, London, UK). A Paar (Anton Paar KG, Austria) pressurized MW decomposition (PMD) system, fitted with an exhaust, cooling device, and a pressure control mechanism that is used to switch off the MW energy at a pressure of about 80 bar was used for decomposing bovine liver samples. The MW system offers a maximum power of 750 W. An ultrasonic bath (Ultrasons, J.P. selecta, Barcelona, Spain) was used for agitating and homogenizing the slurries prior to analyses. A Malvern Mastersizer 2000 particle size analyser 
(Malvern Instruments, Malvern, UK), which is based on the principle of laser diffraction, was used to determine the particle size distribution.

Sample, chemicals and reagents

Fresh bovine liver sample of unknown origin purchased from a local butchery and a lyophilised National Institute of Standards and Technology (NIST) bovine liver CRM 1577b were studied. Suprapur grade $\mathrm{HNO}_{3}$ (Merck, Darmstadt, Germany) was used for the preparation of slurries as well as for the MW digestion of bovine liver samples. Calibration standards were prepared by serial dilution of analytical grade (AR) $1000 \mu \mathrm{g} . \mathrm{mL}^{-1}$ stock standard solutions (Fluka A.G., Switzerland) to the required working concentration range. All solutions were prepared in distilled water passed through a Milli-Q de-ionizing system (Millipore, Milford, MA, USA).

\section{Grinding procedure}

The first treatment phase of the bovine liver sample included washing the sample with deionised water followed by lyophilisation to constant mass with an in-house made freeze drier. Freezedried liver chunks were then milled, to reduce the size of the chunks, using a multipurpose food processor followed by fine grinding of the freeze-dried bovine liver.

Approximately $2 \mathrm{~g}$ of the milled sample was weighed and transferred into a clean and dry milling vessel containing agate beads. The plastic milling vessel containing the milled bovine liver and grinding beads was placed in the micronizing mill and the contents ground for the required time. No solvent was added during grinding. An appropriate portion of the powdered sample was used for the preparation of slurries or digests as described below.

\section{Sample preparation procedures}

Three sample preparation procedures (slurry method, aqueous extraction and MW acid digestion) were compared, to evaluate the possibility of using slurry nebulization as a viable alternative.

Slurry preparation. The slurries were prepared by accurately weighing $500 \mathrm{mg}$ of freeze-dried and ground bovine liver powder. The samples were quantitatively transferred into $50 \mathrm{~mL}$ volumetric flasks and made up to the mark with $2.0 \mathrm{M} \mathrm{HNO}_{3}$ for the determination of $\mathrm{Cu}, \mathrm{Fe}$, $\mathrm{Mg}, \mathrm{Mn}$ and $\mathrm{Zn}$. No dispersing agents were further added to the slurries. Slurries were prepared in triplicate and homogenized by sonication for $30 \mathrm{~min}$.

Aqueous extraction. Slurries were prepared following the procedure developed above and sonicated for $1 \mathrm{~h}$ while maintaining a constant temperature of $50{ }^{\circ} \mathrm{C}$ in closed volumetric flasks. The contents were passed through a $0.45 \mu \mathrm{m}$ membrane filter while still warm. The filtrate was collected, without dilution, for direct analysis by ICP-OES.

Microwave assisted acid digestion. A $250 \mathrm{mg}$ portion of freeze-dried and ground bovine liver powder was accurately weighed and transferred into a quartz digestion vessel. Concentrated $\mathrm{HNO}_{3}(2.00 \mathrm{~mL})$ was added and the solution was digested only after the initial reaction has subsided. Digestion was carried out for 10 min using microwave program recommended by the instrument manufacturer for the digestion of biological samples.

After decomposition, the sample was allowed to cool down and transferred into a $25 \mathrm{~mL}$ volumetric flask and made up to the mark with deionized water. A blank solution was prepared by digesting $2.00 \mathrm{~mL} \mathrm{HNO}_{3}$ (conc.) using the procedure described above. The digested acid was diluted to $25 \mathrm{~mL}$. All digestions were prepared in triplicate. 


\section{RESULTS AND DISCUSSION}

\section{Particle size measurement}

Previous studies have demonstrated that the signal response was strongly dependent on particle size for the nebulizer-based slurry introduction technique [18]. Bovine liver was initially freezedried to facilitate ease of transportation, storage and grinding. Freeze-dried bovine liver contains a small amount of fat, which could have an effect on grinding and production of suitably sized particles. To study the effect of grinding time on the particle size distribution, freeze-dried bovine liver was ground for $0.5,1,2$ or $3 \mathrm{~h}$ and the resulting powder was dispersed in propan-2ol and particle size was measured with the Malvern particle size analyser. The analyzer measures mean diameter of Gaussian distribution of solvated particles present in slurries based on laser ensemble light scattering. It is the size of these solvated particles that becomes of interest in elemental analysis as it represents the aerosol population which could possibly reach the plasma and be converted into atoms and ions for subsequent measurement of emitted light intensities.

Grinding the bovine liver for $0.5 \mathrm{~h}$ yielded particles with an average size of $7.32 \mu \mathrm{m}$. Further grinding for 1,2 or $3 \mathrm{~h}$ yielded a gradual decrease in particle size. For example, grinding the bovine liver for $1 \mathrm{~h}$ yielded particles with an average size of $6.53 \mu \mathrm{m}$ while $2 \mathrm{~h}$ grinding reduced the average particle size to $6.44 \mu \mathrm{m}$. Similarly, grinding the sample for $3 \mathrm{~h}$ yielded particles with an average size of $6.23 \mu \mathrm{m}$ (Figure 1). Since longer grinding times did not reduce the average size of the particles significantly, $1 \mathrm{~h}$ grinding time sufficed for the determination of trace metals in bovine liver by slurry nebulization-ICP-OES method.

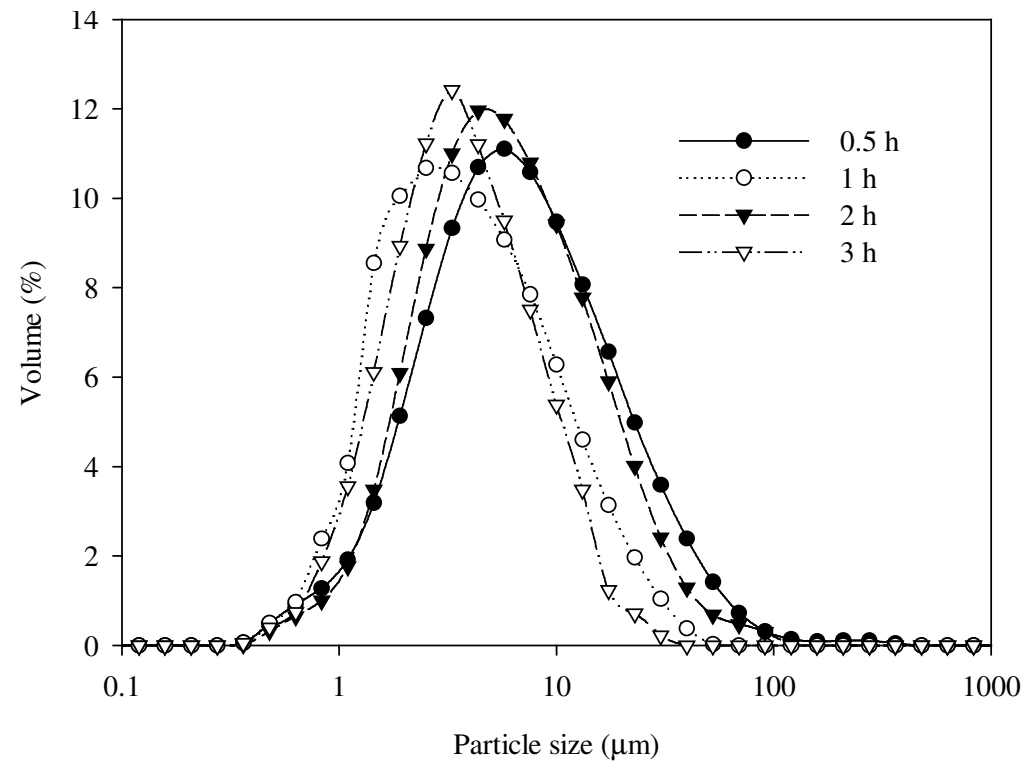

Figure 1. Particle size distribution in slurries prepared from bovine liver sample ground for 0.5 ,

$$
1,2 \text { and } 3 \mathrm{~h} \text {. }
$$

While the analysis of metals in bovine liver was carried out in slurries prepared in nitric acid, the determination of particle size was made in propan-2-ol medium. This was done to avoid corrosion of the metallic parts of the particle size analyser. Therefore, the particle size obtained in propan-2-ol medium may not be identical to that obtained in nitric acid.

Bull. Chem. Soc. Ethiop. 2008, 22(3) 
Nevertheless, the observed smooth uptake rate of slurries prepared in $\mathrm{HNO}_{3}$ provided indirect evidence for formation of particles of desirable size in nitric acid medium.

Effect of nitric acid concentration on the dispersion of slurry particles

Commonly used organic dispersing agents such as Triton X-100 did not yield well dispersed slurries of the bovine liver sample. Similarly, the use of inorganic acids such as $\mathrm{HCl}$ and $\mathrm{H}_{2} \mathrm{SO}_{4}$ did not form good slurries. Nitric acid is well known as a reagent used for preparation of suspensions as well as mobilizing the analytes, with varying degrees of efficiency, from solid particles into the aqueous phase $[4,8,17,20]$. Thus, nitric acid was studied as a chemical aid in the preparation of bovine liver slurries. To study effect of nitric acid, slurries were prepared from bovine liver ground for $1 \mathrm{~h}$ in $0.5,1.0,2.0,4.0$ and $6.0 \mathrm{M} \mathrm{HNO}_{3}$ and the results are shown in Figure 2.

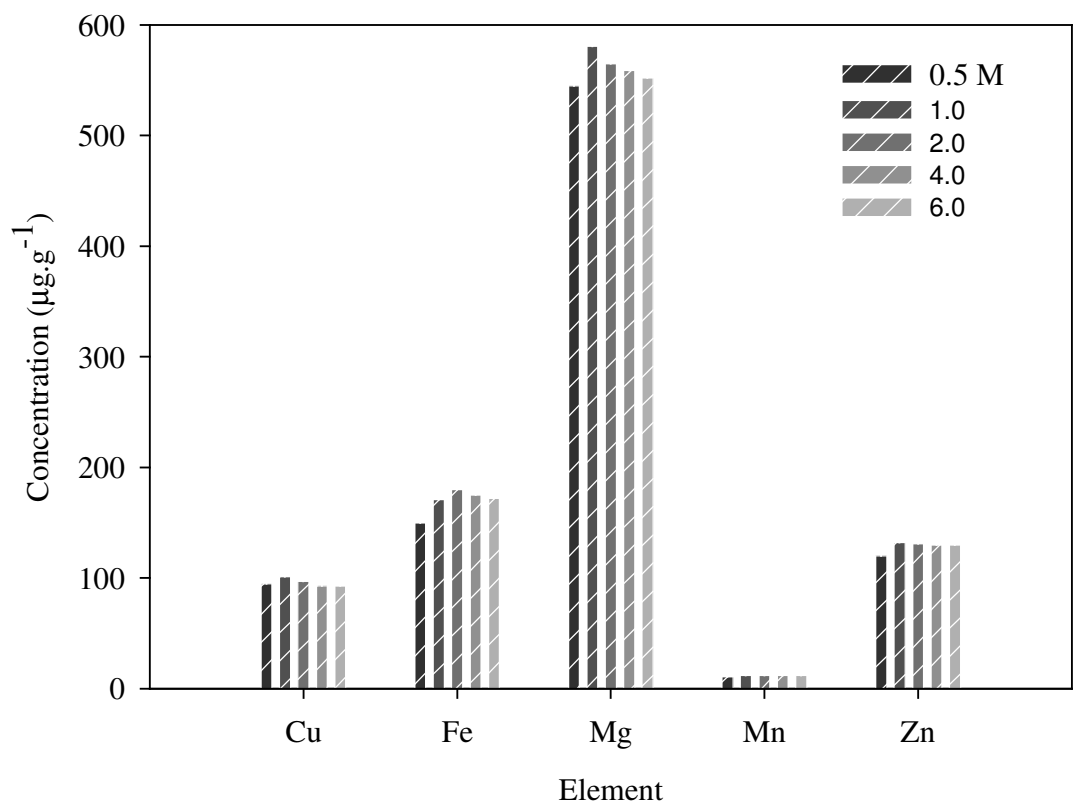

Figure 2. The effect of nitric acid concentration on the concentrations of $\mathrm{Cu}, \mathrm{Fe}, \mathrm{Mg}, \mathrm{Mn}$ and $\mathrm{Zn}$ in bovine liver slurries prepared from material ground for $1 \mathrm{~h}$.

Lower recoveries were achieved for all the elements with $0.5 \mathrm{M} \mathrm{HNO}_{3}$, while on the other hand better results were obtained with $1.0 \mathrm{M} \mathrm{HNO}_{3}$ for all the elements except Fe. However, results were poorly reproducible for slurries prepared in $1.0 \mathrm{M} \mathrm{HNO}_{3}$. With $2.0 \mathrm{M} \mathrm{HNO}_{3}$, stable slurries were formed, improving the transportation efficiency of the slurry into the plasma and hence the reproducibility of results for all elements. This was demonstrated by the good precision obtained (RSD $<1.4 \%$ for all elements). Increasing the $\mathrm{HNO}_{3}$ concentration up to 6.0 $\mathrm{M}$ did not improve the results. Based on the results obtained above, slurries for subsequent analyses were prepared from freeze dried bovine liver ground for $1 \mathrm{~h}$ using $2.0 \mathrm{M} \mathrm{HNO}_{3}$. 
Effect of slurry solid concentration

In ICP-OES when using slurry nebulization, slurry solid concentration is one of the key parameters, because high solid concentration results in decreased analytical signals with time as well as matrix induced non-spectroscopic interferences $[4,18]$. Bovine liver slurries ranging from 0.05 to $1.0 \%(\mathrm{~m} / \mathrm{v})$ were prepared and emission intensities measured. The relationship between the slurry solid concentration and the emission intensities for the analysis of different concentrations of bovine liver slurries is shown in Figure 3. A linear relationship was observed for all the analytes for slurry concentrations of up to $1.0 \%(\mathrm{~m} / \mathrm{v})$. Slurry concentrations higher than $1.0 \%(\mathrm{~m} / \mathrm{v})$ were not studied because detection of analytes was achieved with good reproducibility in the range 0.05 to $1.0 \%(\mathrm{~m} / \mathrm{v})$. This indicates that slurry concentrations of up to $1.0 \%(\mathrm{~m} / \mathrm{v})$ do not cause signal suppression or enhancement.

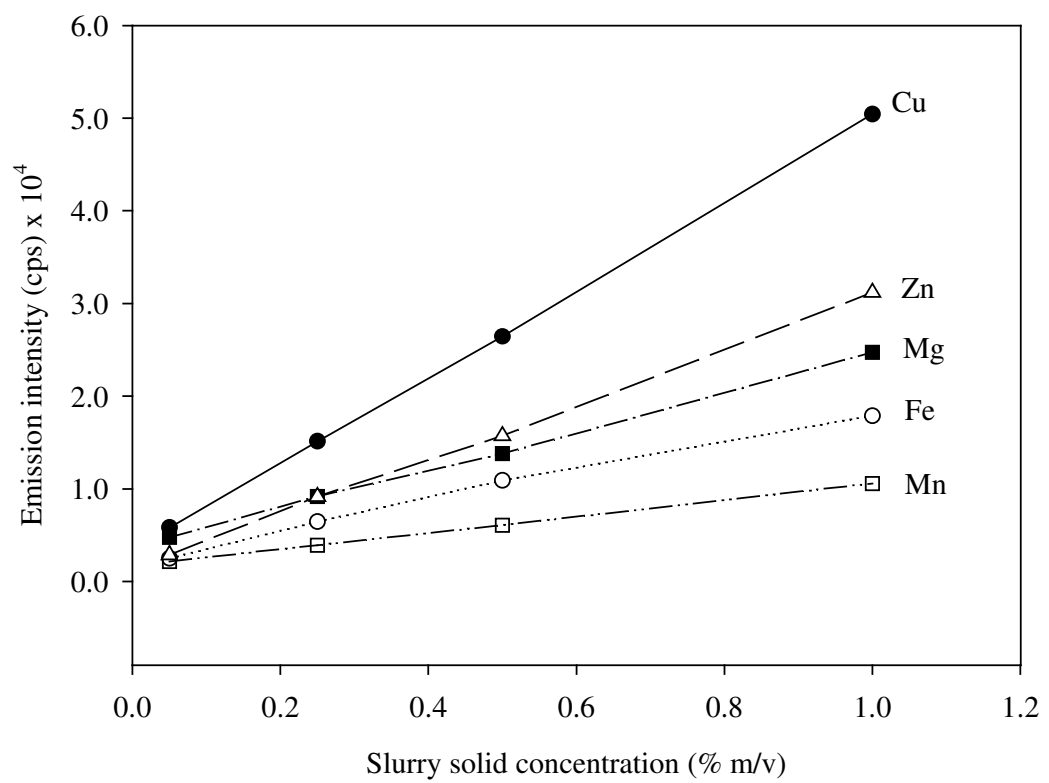

Figure 3. The effect of slurry concentration on emission intensities of $\mathrm{Cu}, \mathrm{Fe}, \mathrm{Mg}, \mathrm{Mn}$ and $\mathrm{Zn}$.

Figure 4 shows the behaviour of emission intensities, for $\mathrm{Cu}, \mathrm{Fe}, \mathrm{Mg}, \mathrm{Mn}$ and $\mathrm{Zn}$, as a function of analysis time. A $1.0 \%(\mathrm{~m} / \mathrm{v})$ slurry was continuously nebulized without agitation and the emission intensity measured at about 3 min intervals. It was observed that emission intensities are stable over $20 \mathrm{~min}$, with no significant loss in sensitivity and no clogging of the nebulizer. Mochizuki et al. [18] obtained a similar effect when testing the stability of a bovine liver CRM slurry using ICP-MS. Even though it was not mentioned whether slurries were agitated or not, slurries of up to $1.0 \%(\mathrm{~m} / \mathrm{v})$ could be nebulized efficiently for $100 \mathrm{~min}$ with no significant loss in sensitivity. This was attributed to a low content of refractory inorganic compounds in bovine liver. 


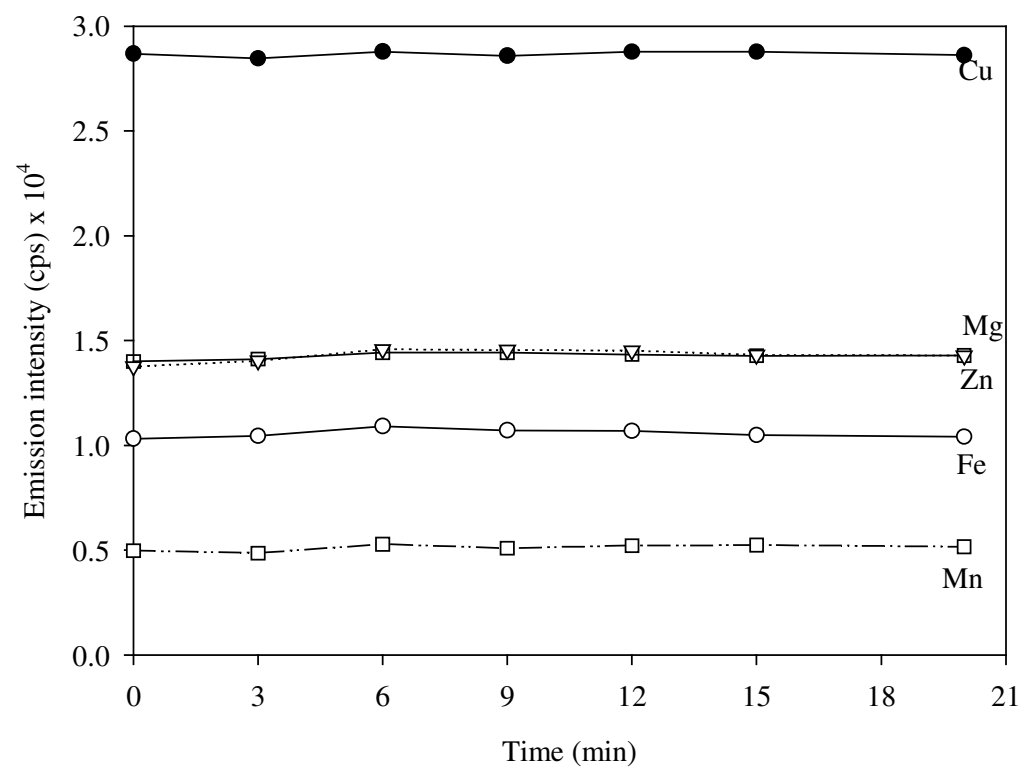

Figure 4. Signal stability of $\mathrm{Cu}, \mathrm{Fe}, \mathrm{Mg}, \mathrm{Mn}$ and $\mathrm{Zn}$ in a $1.0 \%(\mathrm{~m} / \mathrm{v})$ bovine liver slurry.

Analytical results

Table 2 reports the results for $\mathrm{Cu}, \mathrm{Fe}, \mathrm{Mg}, \mathrm{Mn}$ and $\mathrm{Zn}$ in bovine liver, using the slurry method and comparing them to those obtained using aqueous extraction and acid assisted MW digestion methods. Calibration of the spectrometer was performed using aqueous standard solutions. The slurry method was evaluated as an alternative for the analysis of bovine liver by statistical comparison to the mean values obtained using aqueous extraction and acid assisted MW digestion methods. When using the aqueous extraction technique, $\mathrm{Cu}, \mathrm{Mg}, \mathrm{Mn}$ and $\mathrm{Zn}$ were totally extracted into the aqueous medium. The extraction of Fe was lower by $19 \%$ compared to the concentrations determined by the slurry and microwave digestion techniques. This could be attributed to the fact that iron in liver is associated with heme or non-heme iron containing proteins such as iron transport and storage proteins, transferrin and ferritin, respectively. Although several metals can bind to transferrin, it however, has the highest affinity for the ferric $\left(\mathrm{Fe}^{3+}\right)$ form of iron. Iron(III) is less soluble in the acidic medium used for the extraction of metals in liver sample [21]. Thus, the incomplete dissolution of $\mathrm{Fe}$ in bovine liver in $2.0 \mathrm{M}$ $\mathrm{HNO}_{3}$ may be attributed to this strong binding.

Table 2. Comparison of concentrations of metals in bovine liver determined using slurry nebulization, aqueous extraction and MW digestion. $(\mathrm{n}=3)$.

\begin{tabular}{|c|c|c|c|}
\hline Element & Slurry nebulization & Aqueous extraction & MW digestion \\
\hline & Mean $\left(\mu \mathrm{g} \cdot \mathrm{g}^{-1} \pm \mathrm{SD}\right)$ & Mean $\left(\mu \mathrm{g} \cdot \mathrm{g}^{-1} \pm \mathrm{SD}\right)$ & Mean $\left(\mu \mathrm{g} \cdot \mathrm{g}^{-1} \pm \mathrm{SD}\right)$ \\
\hline $\mathrm{Cu}$ & $93.5 \pm 0.5$ & $97.7 \pm 1.2$ & $94.3 \pm 0.7$ \\
$\mathrm{Fe}$ & $160 \pm 4$ & $130 \pm 7$ & $160 \pm 5$ \\
$\mathrm{Mg}$ & $560 \pm 7$ & $620 \pm 10$ & $590 \pm 9$ \\
$\mathrm{Mn}$ & $11.0 \pm 0.26$ & $11.4 \pm 0.3$ & $12.0 \pm 0.3$ \\
$\mathrm{Zn}$ & $130 \pm 2.0$ & $143 \pm 3$ & $132 \pm 2.3$ \\
\hline
\end{tabular}


Since the slurry method is an iron-species independent technique, the results obtained using this method can be regarded as realistic. Techniques based on extraction of species may not completely remove metal ions because they may be selective to certain species. This may account for poor recoveries of metals reported in the literature [22]. Both the slurry coupled with the Burgener high solids nebulizer and acid digestion techniques reflect total elemental concentrations. The slurry method gave results for $\mathrm{Cu}, \mathrm{Fe}, \mathrm{Mn}$ and $\mathrm{Zn}$ that are comparable at $95 \%$ confidence level (CL) to those obtained by the MW digestion method. The result obtained for $\mathrm{Mg}$ using the slurry technique was slightly lower $(<5 \%)$ than that obtained by acid digestion. However, the value should be acceptable as it is within experimental error.

The accuracy and precision of the slurry method was checked by analysing a NIST bovine liver CRM 1577b, using aqueous standard solutions for calibration. The results are listed in Table 3. Statistical evaluation using the student's $t$-test at $95 \% \mathrm{CL}$ showed that the results obtained using the slurry method are in good agreement with the certified values. These results demonstrate efficient nebulization and atomization of slurry particles in nitric acid medium and justifies the use of aqueous standards since the size of the particles in the slurry are sufficiently small enough to effect efficient transportation meaning that loss is minimized.

Table 3. Comparison of analytical results determined using the slurry method with certified values for metals in NIST bovine liver CRM 1577b $(\mathrm{n}=3)$.

\begin{tabular}{|c|c|c|}
\hline Element & $\begin{array}{c}\text { Slurry nebulization } \\
\text { Value obtained }\left(\mu \mathrm{g} \cdot \mathrm{g}^{-1} \pm 1 s\right)\end{array}$ & $\begin{array}{c}\text { Certified value } \\
\left(\mu \mathrm{g} \cdot \mathrm{g}^{-1} \pm 1 s\right)\end{array}$ \\
\hline $\mathrm{Cu}$ & $155 \pm 2$ & $160 \pm 8$ \\
$\mathrm{Fe}$ & $178 \pm 3$ & $184 \pm 15$ \\
$\mathrm{Mg}$ & $605 \pm 10$ & $601 \pm 28$ \\
$\mathrm{Mn}$ & $8.95 \pm 0.12$ & $10.5 \pm 1.7$ \\
$\mathrm{Zn}$ & $128 \pm 2$ & $127 \pm 16$ \\
\hline
\end{tabular}

\section{CONCLUSIONS}

The results obtained for the analysis of $\mathrm{Cu}, \mathrm{Fe}, \mathrm{Mg}, \mathrm{Mn}$ and $\mathrm{Zn}$ in bovine liver using slurry nebulization showed that it is possible to determine trace metal concentrations in bovine liver without the need to dissolve and/or filter the sample prior to analysis. This study further demonstrated the incapability of the aqueous $\mathrm{HNO}_{3}$ extraction procedure to completely transfer metals that are strongly bound to the biological matrix into the aqueous phase. This fact explains the observed lower results for $\mathrm{Fe}$ in aqueous extracts of bovine liver. Moreover, the stability of slurries is an important feature since it represents homogeneity, which improves accuracy and precision of the analytical data. Additional significant features of the slurry technique include the possibility of using aqueous standards for tracing calibration curves and reduction of contamination as revealed by good precision of analytical results. Thus, the slurry method can be applied as an alternative, effective, safe and simple procedure for the pre-treatment of bovine liver for analysis by ICP-OES.

\section{AKNOWLEDGEMENTS}

The authors gratefully acknowledge the financial support of the National Research Foundation and the Department of Labour, RSA. 


\section{REFERENCES}

1. Sedki, A.; Lekouch, N.; Gamon, S.; Pineau, A. Sci. Total. Environ. 2003, 317, 201.

2. Godal, A.; Langseth, L.; Sivertsen, T.; Lund, W. Sci. Total. Environ. 1995, 168, 249.

3. Flandysz, F. Food Addit. Contam. 1991, 8, 71.

4. Marcó, M.L.P.; Hernández Caraballo, E.A.; Pascusso, C.; Alvardo, J. Talanta 2003, 59, 897.

5. Yang, Z.; Hou, X.; Jones, B.T.; Sane, D.C.; Thomas, M.J.; Schwenke, D.C. Microchem. J. 2002, 72, 49.

6. Andrási, E.; Igaz, S.; Szoboszlai, N.; Farkas, E.; Ajtony, Z. Spectrochim. Acta Part B 1999, $54,819$.

7. Garg, A.N.; Chutke, N.L.; Ambulkar, M.N.; Dogra, R.K.S. Appl. Radiat. Isot. 1996, 47, 581.

8. Niazi, S.B.; Littlejohn, D.; Halls, D.J.; Analyst 1993, 118, 821.

9. Trevizan, L.C.; Nogueira, A.A.; Nóbrega, J.A. Talanta 2003, 61, 81.

10. Marcó, L.M.P.; Copote, T.; Hernández, E.A.; Greaves, E.D. Spectrochim. Acta Part B 2001, $56,2187$.

11. Caroli, S.; Spagnoli, M.; Forte, G.; Alessandrelli, A.; Cresti, R.; D’Ilio, S.; Pauwels, J.; Kramer, G.N.; Záray, G. Microchem. J. 2000, 67, 235.

12. Zhou, C.Y.; Wong, M.K.; Koh, L.L.; Wee, Y.C. Talanta 1996, 43, 1061.

13. Kingston, H.M.; Jassie, L.B. Anal. Chem. 1986, 58, 2534.

14. Abu-Samra, A.; Morris, J.S.; Koirtyohann, S.R. Anal. Chem. 1975, 478, 1475.

15. Kingston, H.M.; Jassie, L.B. (Eds.), Introduction to Microwave Sample Preparation. Theory and Practice, American Chemical Society: Washington, DC; 1988.

16. Martins, P.; Pozebon, D.; Dressler, V.L.; Kemieciki, G.A. Anal. Chim. Acta 2002, 470, 195.

17. Alves, F.L.; Smichowski, P.; Farías, S.; Marrero, J.; Arruda, M.A.Z. J. Braz. Chem. Soc. 2000, $11,364$.

18. Mochizuki, T.; Iwata, S.H.; Ishibashi, Y.; Gunji, N. Fresenius J. Anal. Chem. 1991, 339, 889.

19. Fagioli, F.; Landi, S.; Locatelli, C.; Righini, F.; Settimo, R. J. Anal. Atom. Spectrom. 1990, $5,519$.

20. Bermejo-Barrera, P.; Moreda-Piñeiro, A.; Moreda-Piñeiro, J.; Bermejo-Barrera, A. Talanta 1998, 45, 1147.

21. King, M.W. Iron, Heme and Porphyrin Metabolism. The medical biochemistry page, Website: http://web.indstate.edu/thcme/mwking/heme-porphyrin.html, accessed October 10, 2007.

22. De Boer, J.L.M.; Maessen, F.J.M.J. Spectrochim. Acta Part B 1983, 38, 739. 